\title{
A DINÂMICA INTERATIVA E O PROCESSO DE APRENDIZAGEM NO APL DE SOFTWARE DE CURITIBA NO CONTEXTO DO SI
}

\author{
Pollyanna Rodrigues Gondin ${ }^{1}$ \\ Walter Tadahiro Shima ${ }^{2}$
}

\begin{abstract}
Resumo: O presente trabalho tem como objetivo analisar os processos de interação e cooperação, tanto formal quanto informal que ocorrem no polo de TIC de Curitiba. Busca-se verificar o grau de interação, cooperação e consequente aprendizado entre os diversos atores, bem como suas formas e os impactos das mesmas para as empresas. Para a realização desse estudo, a metodologia de pesquisa desenvolvida foi a qualitativa, sendo a técnica empregada pautada em entrevistas orientadas por questionário, que foram realizadas nas empresas e em instituições de apoio pertencentes ao polo no ano de 2016. Concluiu-se que na aglomeração estudada, existe um esforço e um aparato institucional voltado para o apoio às empresas da aglomeração. Esse aparato envolve várias instituições, entretanto, as mais citadas pelas empresas foram a CENETIC e o SEBRAE. Apesar disso, a impressão é que o polo é sustentado pela colaboração espontânea que ocorre entre os associados, já que são estes os próprios governantes da aglomeração e CENETIC, além do que a interação com as universidades é ínfima. Nota-se com a pesquisa de campo desse aglomerado que a maioria das parcerias são para resolver lacunas internas às empresas bem como desenvolver inovações de processo nas mesmas.
\end{abstract}

Palavras-chave: Tecnologia da Informação e Comunicação (TIC). Interação. Aprendizado. Inovação.

\begin{abstract}
The present work aims to analyze the processes of interaction and cooperation, both formal and informal that occur in the ICT center of Curitiba. It seeks to verify the degree of interaction, cooperation and consequent learning between the different actors, as well as their forms and the impacts of the same for the companies. In order to carry out this study, the research methodology developed was qualitative, and the technique used was based on questionnaire-based interviews, which were carried out in companies and support institutions belonging to the pole in 2016. It was concluded that in the agglomeration studied, there is an effort and an institutional apparatus aimed at supporting agglomeration companies. This apparatus involves several institutions, however, the most cited by the companies were CENETIC and SEBRAE. Despite this, the impression is that the cluster is sustained by the spontaneous collaboration that takes place among the associates, since these are the very rulers of the agglomeration and CENETIC, in addition to that the interaction with the universities is very small. It is noted with the field research of this cluster that the majority of the partnerships are to solve internal gaps to the companies as well as to develop innovations of process in the same.
\end{abstract}

Key-words: Information and Communication Technology (ICT). Interaction. Learning. Innovation.

Área ABEIN 3.4: Estratégias e gestão da C\&T\&I. Classificação Journal Economic Literature (JEL): O Economic Development, Innovation, Technological Change, and Growth.

\footnotetext{
1 Pós-Doutoranda no Programa de Pós-Graduação em Políticas Públicas da Universidade Federal do Paraná. E-mail: pollygondin@gmail.com

2 Professor no Programa de Pós-Graduação em Políticas Públicas da Universidade Federal do Paraná. E-mail: waltershima@ufpr.br
} 


\section{INTRODUÇÃO}

A concentração geográfica e setorial de empresas, característica dos polos tecnológicos, além de gerar externalidades produtivas, aumenta a capacidade de avanço tecnológico (BRITTO; ALBUQUERQUE, 2002). Isso ocorre, pois permite a intensificação de articulações e interações que podem ter impactos relevantes na geração de efeitos de aprendizado e na dinamização do processo inovativo em escala local e/ou regional.

De acordo com Britto (1999), o aprendizado é visto como o processo por meio do qual as firmas ampliam seus estoques de conhecimento, aperfeiçoam seus procedimentos de busca e refinam suas habilidades em desenvolver ou manufaturar produtos. Esse aprendizado decorre da capacitação tecnológica acumulada internamente e de conhecimentos desenvolvidos externamente ou copiados e pode atuar como fundamental para a ocorrência de inovação de produto.

No Brasil, os estudos sobre aglomerações de empresas, passaram a ganhar importância a partir do final da década de 90, dado a crescente necessidade de formular novas políticas industriais que levassem em consideração questões específicas brasileiras e que contribuíssem para a implementação de políticas de desenvolvimento industrial, tecnológico e regional, servindo para orientar o desenvolvimento produtivo e inovativo. Assim, devido à grande importância desse assunto para as políticas públicas de desenvolvimento industrial, tecnológico e regional, a proposta de estudo deste trabalho gira em torno da temática de aglomerações de empresas, verificando os processos de interação, cooperação e inovação.

$\mathrm{O}$ setor de TIC foi escolhido para a pesquisa uma vez que é considerado estratégico para o desenvolvimento das economias, devido à sua grande dinâmica e a baixa necessidade de investimento em capital, pois não demanda grande investimento em infraestrutura física por parte das empresas. Além disso, esse setor apresenta um caráter transversal, o que contribui para a geração de externalidades e para que impacte os demais setores da economia, permitindo, segundo Tigre (2005), o surgimento de uma onda de inovações secundárias, que pode revolucionar a organização do sistema produtivo global.

Levando em consideração esta contextualização, o presente trabalho tem como objetivo a análise dos processos de interação e cooperação, tanto formal quanto informal que ocorre no polo de TIC de Curitiba. Busca-se verificar o grau de interação, cooperação e consequente aprendizado entre os diversos atores, bem como suas formas e os impactos das mesmas para as empresas, verificando os fatores institucionais e econômicos que potenciam a inovação. Apoiando-se no quadro teórico das aglomerações de empresas, mais especificamente dos Arranjos Produtivos Locais (APLs), e do processo de aprendizagem propiciado por este tipo de aglomeração, pretende-se mostrar a relevância da interação e do processo de aprendizagem, para geração do conhecimento no reforço de efeitos espontâneos de potenciação da inovação.

Para a realização desse estudo, a metodologia de pesquisa desenvolvida foi a qualitativa, sendo a técnica empregada pautada em entrevistas orientadas por questionário, que foram realizadas nas empresas e em instituições de apoio pertencentes ao polo no ano de 2016. Com o intuito de cumprir com o objetivo, este trabalho se divide em três seções, para além desta introdução e das considerações finais. Inicia-se com uma breve revisão teórica das aglomerações de empresas e do processo de aprendizagem rumo a geração de conhecimento. Na sequência, parte-se para a metodologia, apresentando o caminho seguido desde a aplicação dos questionários. A terceira seção, por sua vez, refere-se ao estudo de caso do polo de Curitiba adentrando-se em temas como interação, aprendizado, cooperação e inovação.

\section{REFERENCIAL TEÓRICO}

Levando em consideração a relevância, a incerteza e a complexidade que envolvem o processo inovativo, esta seção desdobra-se no estudo do significado da inovação tecnológica, bem como com temáticas relacionadas a este fim, como por exemplo, aprendizagem por interação e a geração de conhecimento, e o papel das instituições de apoio no processo inovativo. A inovação tecnológica ganhou destaque no debate acadêmico pelos escritos schumpeterianos e suas posteriores interpretações por autores neoschumpeterianos. 
O objeto de estudo deste trabalho diz respeito à interação entre os diversos agentes na geração de inovação no setor de Tecnologia da Informação e Comunicação (TIC), que supostamente é inovador por definição. A trajetória tecnológica e a capacidade de inovação de uma indústria estão fortemente relacionadas com o arcabouço institucional que conforma o ambiente de seleção, o que torna relevante a noção de sistemas de inovação e a análise das aglomerações de empresas. Diferentemente do que considera o modelo linear, para ocorrer o desenvolvimento tecnológico e a inovação propriamente dita, é necessária a convergência de interesses conflitantes entre os diversos atores envolvidos. Além disso, a dinâmica da inovação é a base do processo de transformação econômica e depende não somente dos recursos destinados para seu fim em si, mas também da difusão tecnológica, do conhecimento e do processo de aprendizagem, que é cumulativo, sistêmico e idiossincrático.

A aglomeração de empresas possibilita que micro e pequenas empresas obtenham vantagens competitivas, uma vez que nesta concentração tende a ocorrer uma maior cooperação, uma maior difusão de conhecimento e de tecnologia, dentre outros fatores, que sustentam o crescimento dessas empresas frente ao mercado. Foi então que, a fim de se entender o desempenho competitivo das empresas, várias teorias passaram a analisar as relações entre as empresas e entre essas e outras instituições que estão inseridas em um mesmo espaço geográfico. Esse enfoque, de acordo com Cassiolato e Lastres (2004), orienta as políticas governamentais destinadas à indústria e à tecnologia na atualidade.

A análise da REDESIST ${ }^{3}$ leva em consideração a visão neoschumpeteriana sobre sistemas de inovação, enfatizando o caráter localizado e específico dos processos de aprendizagem e inovação, além de destacar a questão espacial. De acordo com Cassiolato e Lastres (2004), o conhecimento tácito passa a adquirir grande importância, assim como as instituições e organizações, suas políticas e todo o ambiente sociocultural onde se inserem os agentes econômicos. A consideração desses aspectos determina que a questão da localização geográfica assuma grande relevância para os neoschumpeterianos, na medida em que aspectos intrínsecos à localização influenciarão no processo de geração de inovação de forma decisiva.

Segundo os autores em questão, os Sistemas e Arranjos Produtivos Locais, fundamentam-se na visão evolucionista sobre inovação e mudança tecnológica:

\footnotetext{
- O reconhecimento de que inovação e conhecimento colocam-se cada vez mais visivelmente como elementos centrais da dinâmica e do crescimento de nações, regiões, setores, organizações e instituições;

- A compreensão de que a inovação e o aprendizado, enquanto processos dependentes de interações, são fortemente influenciados por contextos econômicos, sociais, institucionais e políticos específicos;

- A ideia de que existem marcantes diferenças entre os agentes e suas capacidades de aprender, as quais refletem e dependem de aprendizados anteriores;

- A visão de que se, por um lado, informações e conhecimentos codificados apresentam condições crescentes de transferência [...] conhecimentos tácitos de caráter localizado e específico continuam tendo um papel primordial para o sucesso inovativo e permanecem difíceis (senão impossíveis) de serem transferidos (CASSIOLATO; LASTRES, 2004, p. 24).
}

Assim, é a partir dos preceitos da visão evolucionista sobre inovação e mudança tecnológica, que a REDESIST se propõe a caracterizar APLs, levando em consideração o conceito de Sistema de Inovação (SI). Um SI caracteriza-se pela presença de instituições, que tanto conjunta quanto individualmente, colaboram no desenvolvimento de tecnologias, sendo este sistema baseado em conceitos de aprendizagem, interações entre os indivíduos e agentes econômicos, complementaridades, governança, dentre outros. Estudar aglomerações de empresas levando em consideração os sistemas de inovação visa entender como essas aglomerações se organizam para criar competitividade através da inovação tecnológica.

A partir do conceito de SI, a REDESIST desenvolveu os conceitos de Arranjo Produtivo Local (APL) e de Sistema Produtivo e Inovativo Local (SPIL). Esses conceitos foram desenvolvidos para auxiliar na análise das interações entre os agentes econômicos, tanto entre as empresas quanto com instituições públicas e privadas, principalmente aquelas que levam à introdução de novas técnicas e novos produtos. As

\footnotetext{
${ }^{3}$ Rede de Pesquisa em Arranjos e Sistemas Produtivos e Inovativos Locais. É uma rede interdisciplinar que foi formalizada em 1997 e está sediada no Instituto de Economia da Universidade Federal do Rio de Janeiro e que conta com a participação de várias universidades e institutos de pesquisa no Brasil. Disponível em: < http://www.redesist.ie.ufrj.br/> Acesso em: 18/04/2018.
} 
relações entre esses agentes, os fluxos de conhecimento, as políticas voltadas para esse arranjo, o processo de aprendizado, a importância da proximidade geográfica, a identidade cultural e social que são capazes de gerar eficiência e vantagens competitivas para seus agentes são elementos de grande relevância para o estudo dos APLs e dos SPILs.

A REDESIST considera então que APLs são:

Aglomerações territoriais de agentes econômicos, políticos e sociais - com foco em um conjunto específico de atividades econômicas - que apresentam vínculos mesmo que incipientes. Geralmente envolvem a participação e a interação de empresas - que podem ser desde produtoras de bens e serviços finais até fornecedoras de insumos e equipamentos, prestadoras de consultoria e serviços, comercializadoras, clientes, entre outros - e suas várias formas de representação e associação. Incluem também diversas outras instituições públicas e privadas voltadas para: formação e capacitação de recursos humanos (como escolas técnicas e universidades); pesquisa, desenvolvimento e engenharia; política, promoção e financiamento (CASSIOLATO; LASTRES, 2004, p.27).

Já os SPILs são aqueles arranjos produtivos em que

[...] interdependência, articulação e vínculos consistentes resultam em interação, cooperação e aprendizagem, com potencial de gerar o incremento da capacidade inovativa endógena, da competitividade e do desenvolvimento local (CASSIOLATO; LASTRES, 2004, p. 27).

Segundo a REDESIST, pode-se considerar que Arranjos e Sistemas Produtivos e Inovativos Locais abrangem um

[...] conjunto de atores econômicos, políticos e sociais e suas interações, incluindo: empresas produtoras de bens e serviços finais e fornecedores de matérias-primas, equipamentos e outros insumos; distribuidoras e comercializadoras; trabalhadores e consumidores; organizações voltadas à formação e treinamento de recursos humanos, informação, pesquisa, desenvolvimento e engenharia; apoio, regulação e financiamento; cooperativas, associações, sindicatos e demais órgãos de representação (CASSIOLATO; LASTRES; STALLIVIERI, 2009, p.14).

\subsection{O PROCESSO DE APRENDIZAGEM RUMO AO CONHECIMENTO E À INOVAÇÃO}

Tendo em vista que as fontes de conhecimento não são apenas internas à firma, mas também externas, faz-se relevante ressaltar a importância da proximidade entre os agentes e da cooperação e aprendizagem por interação entre os mesmos como estímulo à geração de conhecimento para o processo inovativo. A esse respeito, nota-se que a abordagem evolucionária assume que os agentes possuem um comportamento "proativo" no processo de aprendizagem e que atuam promovendo processos que estimulam o aprendizado, a capacitação e a acumulação contínua de conhecimento (LASTRES; FERRAZ, 1999).

Amorim e Fischer (2013, p. 342), ao afirmarem a relevância do processo de aprendizagem para o processo inovativo, sustentam que:

A capacidade de aprender das organizações, por seu turno, está relacionada ao grau de adesão ou de atrelamento da organização a algum(ns) nó(s) das redes de conhecimento existentes na economia que são voltadas para a inovação. Da mesma forma, a aprendizagem vincula-se à adoção e ao desenvolvimento pelas próprias organizações de práticas de aprendizagem geradoras de conhecimentos.

Britto (1999) afirma que na literatura econômica heterodoxa, o aprendizado é visto como o processo através do qual as firmas ampliam seus estoques de conhecimento, aperfeiçoam seus procedimentos de busca e refinam suas habilidades em desenvolver ou manufaturar produtos. Este 
aprendizado decorre da capacitação tecnológica acumulada internamente e de conhecimento desenvolvidos ou copiados externamente. Lundvall e Johnson (1994) atestam que o aprendizado interativo pode ocorrer tanto entre pessoas quanto entre empresas socialmente inseridas no contexto institucional e cultural de um sistema de inovação. Assim, o principal fator para se criar polos de desenvolvimento é a capacidade local de aprender e inovar em diferentes áreas do conhecimento.

Segundo Lemos (1999, p.133-134), o processo de geração e conhecimento e de inovação implica

[...] o desenvolvimento de capacitações científicas, tecnológicas e organizacionais e esforços substanciais de aprendizado com experiência própria, no processo de produção (learning-by-doing), comercialização e uso (learning-by-using); na busca incessante de novas soluções técnicas nas unidades de pesquisa e desenvolvimento ou em instâncias menos formais (learning-by-searching); e na interação com fontes externas, como fornecedores de insumos, componentes e equipamentos, licenciadores, licenciados, clientes, usuários, consultores, sócios, universidades, institutos de pesquisa, agências e laboratórios governamentais, entre outros (learning-by-interacting).

Pode-se afirmar que existem, assim, dois tipos complementares de processo de aprendizagem. O primeiro diz respeito aos aspectos internos à firma, tais como atividades de P\&D, desenvolvimento a partir de capacitações e rotinas; e o segundo, relaciona-se com a aquisição externa de competências e modelos organizacionais. Logo, considera-se que o processo inovativo ocorre por meio de um processo de interação social. O grau de interação social em que se dá o aprendizado irá variar de acordo com os "agentes envolvidos, o tipo de relação que mantêm entre si, a existência de linguagem comum, identidades, sinergias, confiança, assim como o ambiente em que se inserem" (LEMOS, 1999, p.134).

Além disso, Lundvall (1988) identifica algumas características importantes do processo de aprendizado por interação. Em primeiro lugar, este processo pressupõe a existência de um fluxo sistemático de informações que conecta diferentes agentes. Em segundo lugar, o aprofundamento do aprendizado por interação pressupõe "seletividade" nos relacionamentos interindustriais. Em terceiro lugar, o aprendizado por interação necessita de determinado tempo para se desenvolver. Em quarto lugar, o aprofundamento da interação requer a presença de sistemas de incentivos indutores do processo. Por fim, observa-se que ao longo do tempo, o fortalecimento do relacionamento conduz a consolidação de um espaço econômico particular, inserido em um sistema mais geral de relações interindustriais.

O aprendizado por interação é de grande relevância para que o processo inovativo ocorra. Entretanto, é possível questionar se a aprendizagem, apenas condicionada pela aglomeração territorial, é um processo coletivo que penetra todo o sistema e dissemina o conhecimento (ASHEIM; EJERMO; RICKNE, 2011). Esse questionamento é plausível, já que, pode ocorrer distribuição desigual de aprendizagem e conhecimento devido à heterogeneidade das empresas. Essa heterogeneidade não pode ser totalmente compensada pela proximidade regional com universidades ou outras instituições. A esse respeito pode-se afirmar que o setor de TIC é bastante heterogêneo podendo perpassar todos os setores econômicos, dificultando que o processo de aprendizagem ocorra igualmente entre empresas pertencentes ao mesmo polo.

É possível afirmar que existe uma contradição relevante no estudo dos processos de aprendizagem, já que por um lado, a aprendizagem requer capital social e confiança entre os agentes envolvidos, para a troca de conhecimentos, e por outro, pode acelerar o aumento da desigualdade (FAGERBERG; MARTIN; ANDERSEN, 2013). Isso ocorre, uma vez que a inovação e os processos que levam à esta, são vistos como atividades comuns a empresas de alta tecnologia, às universidades, aos centros de $\mathrm{P} \& \mathrm{D}$, e à economias desenvolvidas. Todavia, desconsidera-se o papel das economias menos desenvolvidas nesse processo.

Assim, estudar o processo de aprendizado que leva à inovação em economias menos desenvolvidas, como Brasil, se configura como importante para entender o papel desta economia no cenário tecnológico internacional. Além disso, o estudo do processo de aprendizado, entre os agentes em economias menos desenvolvidas, é fundamental para o desenvolvimento de políticas públicas que visem a estimular o processo de inovação. Isto posto, reforça-se a relevância do estudo proposto. 


\section{METODOLOGIA}

Visando alcançar o objetivo geral, a metodologia de pesquisa adotada neste trabalho é essencialmente a qualitativa. $\mathrm{O}$ estudo de caso compreendido neste trabalho foi realizado durante o ano de 2016. A população pesquisada compreende a seção J, da Classificação Nacional de Atividades Econômicas (CNAE) 2.0 Revisão 2, que é a classificação oficial adotada pelo sistema Estatístico Nacional e pelos demais órgãos tanto em nível federal, quanto estadual e municipal. A população é constituída por todas as empresas que são associadas ao APL de Software de Curitiba/CENETIC ${ }^{4}$.

Assumiu-se um universo total de 53 empresas, conforme pesquisado no site da instituição e após primeiro contato. Dessas empresas, definiu-se uma amostra de nove empresas. Essa amostra foi definida levando em consideração a pouca aceitação por parte da maioria das empresas e também, a quantidade de pesquisadores envolvidos na realização da pesquisa de campo. Ressalta-se que, a pesquisa de campo foi realizada por apenas um pesquisador, o que, levando em consideração o tempo e disponibilidade das empresas, dificultou o acesso a uma amostra maior. Entretanto, deve-se ressaltar que tal fato não diminui ou invalida a importância dos dados colhidos, uma vez que, durante a pesquisa de campo, observou-se a repetição de eventos e falas.

Para além das empresas, a atenção voltou-se também para algumas instituições que apoiam e participam do polo. Dentre elas, citam-se o próprio APL de Software de Curitiba, a CENETIC, o Serviço Brasileiro de Apoio às Micro e Pequenas Empresas (SEBRAE) e a Associação das Empresas de Tecnologia da Informação, Software e Internet no Paraná (ASSESPRO-PR). Além dessas, foram entrevistadas instituições de ensino e pesquisa, a saber: Universidade Positivo, Pontifícia Universidade Católica do Paraná (PUC-PR) e Instituto Cesar. Salienta-se que o questionário base utilizado foi desenvolvido pela Rede de Pesquisa em Sistemas e Arranjos Produtivos e Inovativos Locais (REDESIST) em 2003. Apesar disso, foram feitas algumas alterações para adaptar à pesquisa.

\section{ANÁLISE DOS RESULTADOS}

O APL de Software de Curitiba é uma instituição sem fins lucrativos que não possui estrutura nem uma personificação jurídica. Tem como objetivo liderar o sistema de TIC com empresas e inovadoras, por meio do reconhecimento local, regional e nacional. É composto pela capital paranaense e alguns municípios da sua região metropolitana, tais como Pinhais, São José, Colombo e Araucária. Conforme Tabela 1, essas cidades totalizam uma população estimada de 2.720.188 de acordo com Instituto Brasileiro de Geografia e Estatística (IBGE). Esse valor representa $24,03 \%$ da população residente no estado do Paraná.

Tabela 1 - População Estimada das Cidades Pertencentes ao Polo de Curitiba

\begin{tabular}{l|c|c}
\hline \multirow{2}{*}{ Cidade } & \multicolumn{2}{|c}{ População estimada em 2017 } \\
\cline { 2 - 3 } & $\mathbf{N}^{\mathbf{0}}$ & $\mathbf{\%}$ \\
\hline Curitiba & 1.908 .359 & $1,86 \%$ \\
\hline Araucária & 137.452 & $2,10 \%$ \\
\hline Colombo & 237.402 & $1,14 \%$ \\
\hline Pinhais & 129.445 & $2,72 \%$ \\
\hline São José dos Pinhais & 307.530 & $75,97 \%$ \\
\hline Demais Cidades & 8.600 .704 & $\mathbf{1 0 0 \%}$ \\
\hline TOTAL PARANÁ & $\mathbf{1 1 . 3 2 0 . 8 9 2}$ & \\
\hline
\end{tabular}

Fonte: Elaboração própria a partir de dados do IBGE (2017).

Pode-se considerar que esse polo possui localização estratégica, uma vez que se encontra em uma região com fácil comunicação e mobilidade ao mercado consumidor, tanto dentro do próprio estado quanto ao mercado de estados vizinhos, como Santa Catarina e São Paulo. Além disso, conta com vários serviços e instituições de ensino e pesquisa, por exemplo, a Universidade Federal do Paraná (UFPR), a Universidade

\footnotetext{
${ }^{4}$ Central de Negócios de Tecnologia da Informação e Comunicação.
} 
Tecnológica Federal do Paraná (UTFPR), a PUC-PR, a Universidade Positivo, o Instituto LACTEC e o Instituto de Tecnologia do Paraná (TECPAR).

Curitiba também conta com um Parque de Software instalado no bairro Cidade Industrial (CIC). Esse parque foi criado para transformar Curitiba e região em um centro de excelência em tecnologia da informação e comunicação. Para cumprir esse objetivo, conta com um espaço físico delimitado para a construção de empresas e infraestruturas prediais, onde se concentram algumas instituições do setor, como a ASSESPRO-PR, além de empresas de menor porte.

Além disso, a região de abrangência do polo possui, aproximadamente, $63 \%$ das empresas de TIC do estado do Paraná, conforme Tabela 2. É possível verificar que a capital Curitiba é a que concentra maior número de estabelecimentos no estado. No que se refere ao pessoal ocupado nas empresas de TIC, 56,99\% concentra-se na região abrangida pelo polo. Ao todo, as empresas de TIC da capital empregam cerca de 56\% do pessoal ocupado em 2014 no estado. Apesar disso, devem-se considerar as limitações dos dados da RAIS, pois essa base de dados não abrange as empresas informais, também conhecidas como empresas "piratas". Nesse setor, a presença de empresas informais é grande e, de acordo com os entrevistados, dificulta a concorrência.

Tabela 2 - Número de empresas e pessoal ocupado no setor de TIC no Paraná e Curitiba em 2014

\begin{tabular}{l|c|c|c|c}
\hline & \multicolumn{2}{|c|}{$N^{\mathbf{0}}$ empresas (CNAE 62 + 63) } & \multicolumn{2}{c}{ Pessoal Ocupado (CNAE 62 + 63) } \\
\hline & $\mathbf{N}^{\mathbf{0}}$ & $\mathbf{\%}$ & $\mathbf{N}^{\mathbf{0}}$ & $\mathbf{\%}$ \\
\hline Curitiba & 5.049 & $56,27 \%$ & 12.954 & $0,23 \%$ \\
\hline Araucária & 80 & $0,89 \%$ & 96 & $0,40 \%$ \\
\hline Colombo & 160 & $1,78 \%$ & 417 & $1,74 \%$ \\
\hline Pinhais & 179 & $1,99 \%$ & 150 & $0,63 \%$ \\
\hline São José dos Pinhais & 144 & $1,60 \%$ & $\mathbf{1 3 . 6 7 4}$ & $\mathbf{5 6 , 9 9 \%}$ \\
\hline Subtotal Curitiba & $\mathbf{5 . 6 1 2}$ & $\mathbf{6 2 , 5 3 \%}$ & 10.318 & $43,01 \%$ \\
\hline Demais Cidades & 3.361 & $37,46 \%$ & $\mathbf{2 3 . 9 9 2}$ & $\mathbf{1 0 0 , 0 0 \%}$ \\
\hline TOTAL PARANÁ & $\mathbf{8 . 9 7 3}$ & $\mathbf{1 0 0 , 0 0 \%}$ & & \\
\hline
\end{tabular}

Fonte: Elaboração própria a partir de dados da RAIS (2016).

O APL de Software de Curitiba começou a ser criado no ano de 2006. Tentativas anteriores de criação desse polo foram realizadas, entretanto, devido a fatores como falta de governança e insuficiência de identidade sociocultural, importantes para a geração de confiança, não obtiveram sucesso (BARATTER; GUARIDO FILHO, 2011). A primeira reunião foi então realizada em maio de 2006, na ASSESPRO-PR. Essa reunião contou com a participação da Secretaria de Estado do Planejamento e Coordenação Geral (SEPL), da Federação das Indústrias do Estado do Paraná (FIEP-PR) e Serviço Brasileiro de Apoio às Micro e Pequenas Empresas (SEBRAE).

Esse polo foi criado como uma necessidade, para atender interesses de diversos atores e instituições, principalmente no que se refere à alavancagem de recursos. O primeiro ano de atuação foi dedicado à elaboração de um plano de ação estratégico e à realização de workshops para atrair os empresários do setor. Em março de 2007, o APL de Software de Curitiba foi oficializado durante um workshop sobre o polo que ocorreu no SEBRAE-PR e contou com a presença de 42 empresários, além de entidades de apoio e governo. Em abril de 2007, foi realizada uma reunião plenária aprovando a estrutura de governança, cronogramas e realizando o início dos trabalhos. Já em 2012, diante da demanda por parte das empresas, por uma instituição para efetuar compras coletivas criou-se a CENETIC.

Ao longo de sua atuação, o APL de Software e a CENETIC estabeleceram parcerias e conquistaram apoiadores. Essas parcerias são importantes para suprir as demandas das empresas associadas, atrair novos associados e dar maior visibilidade ao polo. Esses parceiros desempenham papel relevante em Curitiba, principalmente no atendimento de demanda e interesses de grupos, sendo eles a ASSESPRO-PR, o SEBRAE-PR, e as instituições educacionais, a saber: Universidade Positivo, Pontifícia Universidade Católica do Paraná (PUC-PR) e Instituto Cesar. 


\subsection{PERFIL DAS EMPRESAS ENTREVISTADAS}

Das nove empresas entrevistadas, todas se localizam em Curitiba, sendo que uma delas também possui filial em Araruna, cidade do interior do Paraná. Ademais, duas das empresas entrevistadas possuem localização no Parque de Software da cidade, três localizam-se na região central, uma no bairro Bigorrilho, uma no bairro Jardim Social, uma no Seminário e outra no bairro Novo Mundo. As duas empresas que se localizam no Parque de Software utilizam de salas dessa instituição.

O segmento de atividade principal das empresas concentra-se no código CNAE 62. Todas as empresas da amostra trabalham com o desenvolvimento de softwares. Apesar dessa concentração, deve-se salientar que os softwares desenvolvidos atendem a diversas áreas. Como exemplo, uma das empresas trabalha com desenvolvimento de software para atender corretoras de seguros, outra empresa trabalha com o desenvolvimento de sistema para gestão de laboratórios para análises e ensaios e também, com software para gestão de calibração e metrologia, possuindo como clientes, por exemplo, a FIAT e a Petrobrás. Ademais, existem empresas que desenvolvem sistemas para o setor educacional, para o comércio e indústria, para atender o setor alimentício, para as áreas financeira, gestão de qualidade e logística, dentre outros.

Todas as empresas entrevistadas possuem até 50 funcionários, sendo a amostra bem distribuída no que se refere ao tamanho segundo número de funcionários (Tabela 3). Três empresas desse polo possuem até dez funcionários, outras três possuem de 11 a 20 funcionários, duas empresas possuem de 21 a 30 funcionários e uma empresa possui de 31 a 50 funcionários. Apesar de as empresas que possuem de zero a 20 funcionários serem maioria na amostra, elas são responsáveis por empregar 43,8\% dos trabalhadores. Os dados apresentados pela amostra de empresas vão ao encontro da realidade nacional, de acordo com dados do SEBRAE (2013). Segundo essa instituição, 99\% das empresas brasileiras são de micro e pequeno porte e respondem por $52 \%$ dos empregos com carteira assinada no setor privado.

Tabela 3 - Identificação do porte e do emprego gerado pelas empresas da amostra

\begin{tabular}{c|c|c|c|c}
\hline $\begin{array}{c}\text { Tamanho Segundo no } \\
\text { Funcionários }\end{array}$ & $\mathbf{N}^{\mathbf{0}}$ de Empresas & $\boldsymbol{\%}$ & $\mathbf{N}^{\mathbf{0}}$ de Empregados & \% \\
\hline $0-10$ & 3 & $33,3 \%$ & 21 & $13,5 \%$ \\
\hline $11-20$ & 3 & $33,3 \%$ & 47 & $30,3 \%$ \\
\hline $21-30$ & 2 & $22,2 \%$ & 52 & $33,5 \%$ \\
\hline $31-50$ & 1 & $11,1 \%$ & 35 & $22,6 \%$ \\
\hline TOTAL & $\mathbf{9}$ & $\mathbf{1 0 0 , 0 \%}$ & $\mathbf{1 5 5}$ & $\mathbf{1 0 0 , 0 \%}$ \\
\hline
\end{tabular}

Fonte: Elaboração própria a partir de dados da pesquisa (2016).

Além disso, ressalta-se também que das empresas entrevistadas, 55,5\% foram constituídas na década de 1990. A esse respeito, vale salientar que a empresa com maior número de funcionários, configurase entre as empresas mais antigas da amostra. No que se refere ao perfil do principal sócio-fundador das empresas entrevistadas, deve-se levar em consideração que todos são do sexo masculino, além de que, apenas o sócio-fundador de uma das empresas possuía mais de 51 anos quando da criação da empresa. Além disso, durante as entrevistas, os entrevistados foram questionados sobre a escolaridade dos sócios quando criaram a empresa. A intenção era verificar se a tendência de alta qualificação em setores como TIC era válida no polo. A esse respeito, essa tendência foi confirmada, uma vez que 55,5\% dos sócios possuíam ensino superior completo quando criaram a empresa e 33,3\% possuíam pós-graduação.

\subsection{INTERAÇÃO, APRENDIZADO E COOPERAÇÃO}

A interação entre empresas e instituições no desenvolvimento de atividades, produtos e processos é de grande relevância para o crescimento e desenvolvimento das diversas economias. Isso ocorre uma vez que permite a geração de sinergias para a transferência de conhecimento e tecnologia entre os diversos atores de um aglomerado, podendo levar à geração de inovações. O contexto local será, então, importante 
para a criação de diversas parcerias entre os agentes que visam à interação, à cooperação e à consequente transferência de conhecimento (BROWN; DUGUID, 2001).

No que diz respeito às fontes de informação e aprendizado, as firmas entrevistadas afirmaram que a maior fonte, é o departamento de P\&D interno, que apresentou um índice de relevância ${ }^{5}$ de 0,88 . Em relação às principais fontes de aprendizado e novo conhecimento externo clientes $(0,68)$, outras empresas do grupo $(0,60)$, associações empresariais $(0,57)$ e centros de capacitação privados, como o SEBRAE $(0,52)$ foram os quesitos mais citados. A esse respeito, todas as empresas, em maior ou menor intensidade, citaram os clientes como importante fonte de informação, visto que a produção dos sistemas deve ser adaptada e, muitas vezes, customizada conforme a necessidade deles. Uma das empresas afirmou que "aprende a todo momento com os clientes e como tem informações dos clientes, sabe para onde ir para criar novos produtos". Outra empresa afirmou que a visão do cliente é fundamental no processo de aprendizagem, "pois é o cliente que usará o produto final”. Nota-se a grande importância dos clientes uma vez que as empresas trabalham com o desenvolvimento de software para atender diferentes nichos e setores.

No que se refere às associações empresariais, no APL de Software de Curitiba, a CENETIC, a ASSESPRO, a REDE APL foram as instituições consideradas importantes como fontes de informação. Nesse quesito, algumas das empresas participaram da Missão ao Vale do Silício, nos Estados Unidos, promovida pelo APL de Software de Curitiba/CENETIC. Essa missão, para os que participaram, foi importante fonte de informação e aprendizado desde o processo até a forma de atuação.

É preciso salientar a atuação do SEBRAE, instituição citada em menor ou maior grau por todos os entrevistados. De acordo com Comeli (2017), dentre as ações desenvolvidas pelo SEBRAE para o polo de Curitiba, deve-se ressaltar a disponibilização de espaço físico para a realização das reuniões mensais. Além disso, o SEBRAE atua apoiando e patrocinando a realização de eventos e contratação de palestrantes. Devese ressaltar também que o SEBRAE possui um projeto voltado para atender especificamente as empresas de TIC, o que contribuiu para que muitas empresas procurassem a CENETIC por intermédio do SEBRAE. Durante pesquisa de campo, percebeu-se que o SEBRAE é a instituição que exerce maior peso em termos de informação e aprendizado.

Por outro lado, as universidades e os centros de pesquisa e investigação não foram considerados grandes fontes de informação para o aprendizado. Com a pesquisa de campo, notou-se que o relacionamento com a UFPR, por exemplo, é deficitário e em grande medida não ocorre, principalmente por falta de interesse e visão muito acadêmica. Os interesses e a burocracia envolvida com o meio acadêmico da universidade federal acabam afastando o meio empresarial, principalmente em áreas tecnológicas como TIC, em que há mudanças a todo momento.

No que diz respeito à cooperação propriamente dita, a totalidade das empresas afirmou ter realizado alguma atividade cooperativa entre os anos de 2013 e 2015. Apesar disso, conforme apresentado na Tabela 4, apenas as parcerias com órgãos de apoio e promoção apresentaram índice de relevância superior a 0,50. Parcerias com outras empresas dentro do próprio polo, com outras empresas, clientes, universidades e institutos de pesquisa apresentaram um resultado inferior ao esperado quando se tem cooperação voltada para a inovação.

A respeito das parcerias para cooperação, um dos entrevistados afirmou possuir parceria com outras empresas fora do arranjo com o intuito de gerar inovações tecnológicas. Outro entrevistado afirmou ter parceria com os Institutos LACTEC, outro com a American Chamber of Commerce for Brazil (AMCHAM), além do SEBRAE, empresas do polo, e o próprio APL de Software de Curitiba/CENETIC. Por outro lado, um dos entrevistados afirmou que "acha difícil a parceria para o desenvolvimento de produto". Segundo o entrevistado, isso ocorre até mesmo pelo conflito de interesses entre as partes.

\footnotetext{
${ }^{5}$ Índice de Relevância $=\left(0^{*} \mathrm{~N}^{\circ}\right.$ Nulas $+0,3^{*} \mathrm{~N}^{\circ}$ Baixas $+0,6^{*} \mathrm{~N}^{\circ}$ Médias $+\mathrm{N}^{\circ}$ Altas $) /\left(\mathrm{N}^{\circ}\right.$ Empresas no Segmento $)$. Este índice varia entre 0 e 1 , sendo que quanto mais próximo de 1 estiver, mais importante é o item em questão.
} 
Tabela 4: Parcerias das empresas do APL de Software de Curitiba durante 2013-2015

\begin{tabular}{l|c|c|c}
\hline Agentes & $\begin{array}{c}\text { Índice de } \\
\text { Relevância }\end{array}$ & Formalização & Localização \\
\hline Empresas & 0,37 & $71,4 \%$ & $100 \%$ Curitiba \\
\hline Outras empresas dentro do grupo & 0,23 & $80,0 \%$ & $100 \%$ Brasil \\
\hline Empresas no Brasil & 0,00 & $0,00 \%$ & $100 \%$ Brasil \\
\hline Empresas de Consultoria & 0,13 & $100 \%$ & - \\
\hline Clientes & 0,00 & $0,00 \%$ & $100 \%$ Curitiba \\
\hline Concorrentes & 0,10 & $100 \%$ & $100 \%$ Curitiba \\
\hline Universidades e Institutos de Pesquisa & 0,03 & $100 \%$ & $57,1 \%$ Curitiba \\
\hline Universidades & & & $42,9 \%$ Paraná \\
\hline Outros Agentes & 0,52 & $71,4 \%$ & $100 \%$ Brasil \\
\hline Órgãos de Apoio e Promoção & 0,38 & $100 \%$ & \\
\hline Agentes Financeiros
\end{tabular}

Fonte: Elaborado pelo autor com base em dados da pesquisa (2016).

Quando questionadas sobre as formas de cooperação realizadas, o desenvolvimento de produtos e processos e a cooperação para reivindicações foram os quesitos que apresentaram maior índice de relevância, 0,68 e 0,59 respectivamente. Entretanto, algumas empresas afirmaram ser difícil a parceria para o desenvolvimento de produto, sendo mais comum ocorrer para o desenvolvimento de algum processo interno às empresas ou para a requisição de reivindicações. A respeito das reivindicações, um dos entrevistados afirmou que realiza parcerias com empresas participantes do polo para reivindicar melhorias para o setor de atuação.

O Quadro 1 apresenta uma síntese sobre as principais questões relacionadas à interação, aprendizado e cooperação. Através dele é possível perceber a relevância da P\&D interna e dos clientes como fontes de aprendizado. Foi possível perceber também que as universidades e instituições de ensino não apresentaram grande relevância. Em parte, isso ocorre pelas diferenças de objetivos, o recente histórico de políticas para aglomerações e de inovação no Brasil e também, pela própria característica das atividadesfim das empresas da aglomeração.

Quadro 1: Síntese das Questões Relacionadas à Interação, Cooperação e Aprendizagem

\begin{tabular}{|l|l|}
\hline \multicolumn{1}{|c|}{ Ae Informação e } & \multicolumn{1}{c|}{ APL de Software de Curitiba/CENETIC } \\
\hline $\begin{array}{l}\text { Fontes } \\
\text { Aprendizado }\end{array}$ & $\begin{array}{l}\text { Departamento de P\&D, clientes, outras empresas do grupo, associações empresariais e } \\
\text { centros de capacitação privados (SEBRAE). }\end{array}$ \\
\hline Cooperação & $100 \%$ sim \\
\hline Parcerias para Cooperação & SEBRAE, CENETIC, agentes financeiros, Outras empresas dentro do grupo \\
\hline Formas de Cooperação & $\begin{array}{l}\text { Desenvolvimento de produtos e processos (ênfase em processos), cooperação para } \\
\text { reivindicações. }\end{array}$ \\
\hline $\begin{array}{l}\text { Avaliação dos Resultados das } \\
\text { Ações Conjuntas }\end{array}$ & Melhoria nos processos produtivos e novas oportunidades de negócios. \\
\hline
\end{tabular}

Fonte: Pesquisa de Campo (2015-2016).

No entanto, mesmo reconhecendo a necessidade do estreitamento das relações entre as universidades, empresas e demais instituições, sabe-se que em sistemas de inovação intermediários ou imaturos, tais relações são débeis (SUZIGAN; ALBUQUERQUE, 2008). Isso ocorre, pois, mesmo em instituições de pesquisa e ensino consolidadas, há constrangimentos na mobilização de recursos humanos necessários para gerar expressivos circuitos de retroalimentação positiva entre as dimensões científicas e tecnológicas (RAPINI, et al, 2009). Desse modo, é fundamental que as universidades e os institutos de pesquisa presentes na região sejam capazes de dar suporte ao crescimento observado, a fim de que se formem bases sólidas e sustentáveis para o desenvolvimento regional. A excelência em capacitação tecnológica e científica das universidades, associada às demais instituições, pode constituir polos tecnológicos (VIEIRA; ALBUQUERQUE, 2007). Porém, para que isso ocorra, deve-se estreitar as relações de modo que com o tempo, possa-se ter resultados positivos. 


\subsection{INOVAÇÃO}

De acordo com Cassiolato e Lastres (2004), aspectos relacionados à localização potencializam a interação e a aprendizagem, sendo importantes no processo de geração de inovação. Assim, um dos questionamentos colocados às empresas entrevistadas dedicou-se a investigação das inovações realizadas por elas no período recente. Das empresas entrevistadas, duas afirmaram ter lançado um produto e/ou serviço novo para a empresa, mas já existente no mercado, representando 33,3\% da amostra. Por outro lado, as empresas entrevistadas afirmaram que não desenvolveram nenhum produto e/ou serviço novo para o mercado nacional e internacional, durante os anos de 2013 a 2015.

Dentre os produtos e/ou serviços novos para as empresas, mas já existentes no mercado, cita-se o desenvolvimento de um aplicativo para que a plataforma educacional possa ser acessada via móbile. A empresa em questão já trabalha com sistema para a área educacional, porém inovou para atender a demanda de seus clientes com o aplicativo móbile. Além disso, uma das empresas entrevistadas relatou o desenvolvimento de um processo, MRP, dentro do sistema Enterprise Resourse Planning (ERP), principal produto da empresa. Por meio desse processo, os clientes da empresa em questão podem gerar ordens de produção de acordo com os pedidos de venda, permitindo que se estime a produção segundo as projeções de venda. Uma terceira empresa desenvolveu um aplicativo para monitorar veículo, com controle de revisão, abastecimento, dentre outros. Esse produto foi adquirido por uma grande montadora de automóveis.

Algumas das empresas entrevistadas afirmaram não ter desenvolvido nenhuma inovação de produto no período recente. Porém, dedicam-se a tal atividade atualmente. Uma delas está desenvolvendo um software híbrido para gestão ambiental. Esse software visa a atender uma companhia que cuida da qualidade da água em São Paulo. Posteriormente, pensam em estender esse projeto e desenvolver para outras instituições. Outra empresa está desenvolvendo um software para área de varejo, porém o desenvolvimento está em fase inicial, e estão testando para colocar no mercado. Uma terceira empresa participa da iniciativa SEBRAETEC diferenciação e já pegou cinco projetos para desenvolver.

As empresas também foram questionadas em relação às inovações de processo. A esse respeito, oito das nove empresas entrevistadas desenvolveram algum tipo de inovação de processo novo para a empresa, mas já existente no mercado. Como exemplo, duas das empresas implantaram o MPSBR, um modelo de produção de software do Brasil. Por meio dessa implementação, realizaram uma adequação de processo visando à melhoria na qualidade do produto e na organização da empresa. Outra empresa implantou o MEG, uma inovação de processo para melhorar a capacidade gerencial da empresa, que até então era bem falha. Ainda a respeito das inovações de processo, uma das empresas entrevistadas pertencente ao polo de Curitiba converteu toda a base de dados utilizada na empresa para a linguagem de programação Scala, que, segundo o entrevistado, é muito utilizada por empresas na Europa, mas pouco conhecida entre as empresas do polo. Duas empresas entrevistadas em Curitiba implantaram a nota fiscal eletrônica, o que agilizou o processo interno. Além disso, novos módulos e melhorias nos próprios sistemas utilizados pelas empresas também foram itens citados durante as entrevistas.

As empresas também foram questionadas quanto aos principais impactos gerados pela introdução de inovações. Os índices de relevância dos impactos gerados pela introdução de inovações foram abaixo de 0,50, o que denota sua baixa relevância. Entretanto, os itens que apresentaram índice de relevância maior foram: permitiu que a empresa mantivesse a sua participação nos mercados de atuação, $(0,49)$, aumento da produtividade da empresa $(0,41)$ e aumento da participação no mercado interno da empresa $(0,33)$. A esse respeito, uma das empresas entrevistadas afirmou que a introdução de inovações, tanto de produtos e/ou serviços, quanto de processos, aumentou a participação no mercado interno da empresa e permitiu que a empresa mantivesse sua participação nos mercados de atuação. Outro entrevistado afirmou que a introdução de inovação permitiu a retenção de clientes. A esse respeito, afirmou que "um cliente chegou a adquirir outro produto, mas teve dificuldade no atendimento e voltou para a empresa". 


\section{CONSIDERAÇÕES FINAIS}

A partir da análise dos estudos de caso à luz da aglomeração de empresas e os processos de aprendizagem e interação, buscou-se identificar o papel da interação, do processo de aprendizagem e da geração de conhecimento que ocorre em aglomerações de empresas, em especial, no APL de Software de Curitiba. Para cumprir com o objetivo inicial, a análise do polo de Curitiba adentrou-se nas seguintes temáticas: estrutura e vantagens associadas ao ambiente local, inovação e interação, aprendizado e cooperação.

Em resumo, no polo de TIC de Curitiba, a totalidade das empresas entrevistadas possui classificação de atividade 62, além de ser, em grande medida, empresas de pequeno porte. No APL de Software de Curitiba, observou-se que existe um esforço e um aparato institucional voltado para o apoio às empresas da aglomeração. Esse aparato envolve várias instituições, entretanto, as mais citadas pelas empresas foram a CENETIC e o SEBRAE. Durante a pesquisa de campo foi possível perceber que o SEBRAE apresenta papel relevante, tanto na atração de empresas para as reuniões do aglomerado, quanto na exploração de possibilidades e atuação com o APL de Software de Curitiba e a CENETIC.

Apesar disso, a impressão é que o polo é sustentado pela colaboração espontânea que ocorre entre os associados, já que são estes os próprios governantes da aglomeração e da CENETIC. Somado-se a isso, observou-se com a pesquisa de campo desse aglomerado, que a maioria das parcerias possui como finalidade a resolução de lacunas internas às empresas, bem como o desenvolvimento de inovações de processo nessas. Os dados aqui apresentados também sugerem que o enraizamento local das atividades desenvolvidas pelas empresas de TIC são incipientes. Apesar de universidades como PUC-PR e Universidade Positivo estarem no portfólio de apoios das instituições, elas foram pouco citadas no que se refere ao desenvolvimento conjunto de $\mathrm{P} \& \mathrm{D}$, aprendizado e interação. As instituições de ensino atuam assim, essencialmente, na formação de mão de obra qualificada, uma vez que Curitiba e região metropolitana possuem uma vasta rede de universidades públicas e privadas, além de institutos de pesquisa.

Como dito, predominantemente, as empresas que fazem parte desta aglomeração se dedicam mais a inovação de processo, fato este que poderia ser, em tese modificado, caso houvesse mais interação com universidades e centros de pesquisa que buscassem não apenas a qualificação de mão de obra. Recomendase que trabalhos futuros continuem a estudar a evolução desta aglomeração, ressaltando questões como o financiamento e o papel dos diversos atores no sistema de inovação, sobretudo o papel do governo e das universidades.

\section{REFERÊNCIAS BIBLIOGRÁFICAS}

AMORIM, Wilson Aparecido Costa de; FISCHER, André Luiz. A Aprendizagem Organizacional e suas Bases Econômicas. Nova Economia, Belo Horizonte, 2013. Disponível em: < http://www.scielo.br/pdf/neco/v23n2/04.pdf > Acesso em: 04 de agosto de 2015.

ASHEIM, Bjørn T.; EJERMO, Olof Ejermo; RICKNE, Annika. When is Regional "Beautiful"? Editora: Routledge Taylor \& Francis Group. 2011.

BARATTER, Marystela Assis; GUARIDO FILHO, Edson Ronaldo. Habilidades Sociais no Arranjo Produtivo Local de Software da Cidade de Curitiba. XXXV ANPAD. 2011. Disponível em: <http://www.anpad.org.br/admin/pdf/EOR2485.pdf> Acesso em: 06 de setembro de 2016.

BRITTO, J.; ALBUQUERQUE, E. M. Clusters industriais na economia brasileira: uma análise exploratória a partir de dados da RAIS. Estudos Econômicos, São Paulo, v. 32, n. 1, p. 71-102, 2002 
BRITTO, Jorge Nogueira de Paiva. Características estruturais e modus-operandi das redes de firmas em condições de diversidade tecnológica. 1999. Tese de Doutorado. Universidade Federal do Rio de Janeiro, Instituto de Economia.

BROWN, J. S.; DUGUID, P. Knowledge and Organization: A Social-Practice Perspective. Organization Science, v.12(2), p. 198-213, 2001.

CASSIOLATO, J. E.; LASTRES, H. M. M. O foco em arranjos produtivos e inovativos locais de micro e pequenas empresas. In: LASTRES, H. M. M.; CASSIOLATO, J. E.; MACIEL, M. L. Pequena empresa: cooperação e desenvolvimento local. Relume Dumará Editora. 2004. 21-33 p.

CASSIOLATO, J. E.; LASTRES, H. M. M.; STALliVIERI, F. Introdução: Políticas estaduais e mobilização de atores políticos em arranjos produtivos e inovativos locais. In: CASSIOLATO, J. E.; LASTRES, H. M.M.; STALLIVIERI, F. Arranjos Produtivos Locais: Uma alternativa para o desenvolvimento. Experiências de Políticas. Editora E-Papers. Volume 2. 2009. 11-38 p.

COMELI, L. G. Entrevista concedida à Pollyanna Rodrigues Gondin. Consultor SEBRAE - Gestor do projeto APL de Software de Curitiba e Região, 2017.

FAGERBERG, Jan; MARTIN, Bem R.; ANDERSEN, Esben S. Innovation Studies - Evolution and Future Challenges. Editora: Oxford University Press. 2013.

LASTRES, Helena Maria Martins; FERRAZ, João Carlos. Economia da Informação do Conhecimento e do Aprendizado. In: LASTRES, Helena; ALBAGI, Sarita. Informação e Globalização na Era do Conhecimento. Rio de Janeiro: Campus, 1999, p. 27-57. Disponível em: < http://www.uff.br/ppgci/editais/saritalivro.pdf > Acesso em: 10 de agosto de 2015.

LEMOS, Cristina. Inovação na Era do Conhecimento. In: LASTRES, Helena; ALBAGLI, Sarita. Informação e Globalização na Era do Conhecimento. Editora Campus. 1999.

LUNDVALL, Bengt-Ake. Innovation as an interactive process: from user-producer interaction to the national innovation systems. In: DOSI, Giovanni et al (Eds.), Technical Change and Economic Theory. Pinter, London, 1988.

LUNDVALL, Bengt-Ake.; JOHNSON, B. The learning economy. Journal of Industry Studies, Vol. 1, No. 2, December 1994, pp. 23-42.

RAPINI, M. S. et al. A contribuição das universidades e institutos de pesquisa para o sistema de inovação brasileira. 2009. In: XXXVII Encontro Nacional de Economia. 
SERVIÇO BRASILEIRO DE APOIO ÀS MICRO E PEQUENAS EMPRESAS - SEBRAE. Sobrevivência das Empresas no Brasil - Coleção Estudos e Pesquisas. 2013. Disponível em: < http://www.sebrae.com.br/Sebrae/Portal\%20Sebrae/Anexos/Sobrevivencia_das_empresas_no_Brasil=201 3.pdf> Acesso em: 26 de agosto de 2016.

SUZIGAN, W.; ALBUQUERQUE, E. M. A interação entre universidades e empresas em perspectiva histórica no Brasil. 2008. Texto para discussão UFMG/Cedeplar 329.

TIGRE, P. B. Economia da Informação e do Conhecimento, 2005. Disponível em: <http://ojs.c3sl.ufpr.br>. Acesso em: 7 dez. 2015.

VIEIRA, K. P.; ALBUQUERQUE, E. M. O financiamento às atividades inovativas na região nordeste: uma análise descritiva a partir dos dados da Pintec. 2007. Revista Econômica do Nordeste 38(3). 